\title{
FORMA E SENTIDO DAS ABERTURAS NOS ROMANCES DE SARAMAGO
}

Maria Lúcia Wiltshire de Oliveira Universidade Federal Fluminense

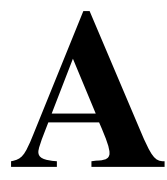

o concluirmos um estudo em torno de seis romances de José Saramago, detectamos uma singular configuração nos capítulos de abertura. Se o sentido deste procedimento soa óbvio por distinguir, numa casa, a porta do seu interior, nem por isso nos parece inútil observar como se revela tal diferença de obra para obra.

Em princípio, Memorial do convento e O ano da morte de Ricardo Reis se assemelham na forma cinematográfica com que são compostos os seus capítulos iniciais. No primeiro, dá-se um close nos aposentos reais; no segundo, pela lente do narrador, opera-se um zoom sobre o personagem que acaba de desembarcar em Lisboa. Na História do cerco de Lisboa e em O evangelho segundo Jesus Cristo a abertura se torna um espaço de tensão, seja para opor duas concepções conflitantes de História - a oficial e a não-oficial -, seja para deflagrar a luta entre dois tempos do universo, - o eterno e o histórico. Por fim, a narrativa se abre por sumários em Levantado do chão e n'A jangada de pedra, sendo o primeiro de natureza retrospectiva, remetido ao passado alentejano, e o segundo de feição recopilativa, voltado para o futuro da península. Vejamos, paulatinamente, as estruturas destes pórticos.

\section{Aproximações cinematográficas}

No Memorial do convento não há prólogo introdutório. O narrador não prepara previamente o leitor. Pelo contrário, 
arremessa-o diretamente no quarto de D. João V, numa certa noite do ano de 1711, em que o soberano freqüentará os aposentos da rainha, sua mulher, "... que chegou (...) da Áustria para dar infantes à coroa portuguesa e até hoje ainda não emprenhou". ${ }^{1}$ Este "hoje" inaugura o tempo da narração e o locus do narrador, dispensandose expedientes generalizantes. O romance começa pelo começo, ou seja, pelas razões que determinaram a construção do convento, mas isso se faz de forma lentificada sob o ponto de vista do duração do tempo narrativo. A contemporaneidade ficcional entre narrador e narração, ou entre discurso e história, inaugurada pelo advérbio, prossegue com a adoção do presente do indicativo cuja função é a de sumariar, de modo singulativo ou iterativo, ${ }^{2}$ o ritual de consórcio sexual dos soberanos.

O ato, que de resto é uma ação estritamente íntima, revestese de valor público e interesse nacional. Usando a máscara do cronista, o narrador se mostra enxerido, divulgando mexericos - "Já se murmura na corte, dentro e fora do palácio, que a rainha, provavelmente, tem a madre seca (...)"3 - e fazendo-se porta-voz, irônico, dos preconceitos da época: "Que caiba culpa ao rei, nem pensar, primeiro porque a esterilidade não é mal dos homens, das mulheres sim, por isso são repudiadas tantas vezes,(...)" ${ }^{4}$

${ }^{1}$ SARAMAGO, 1983, p. 11.

${ }^{2}$ As expressões singulativo e iterativo, de Genette, se aplicam a duas possibilidades de repetição entre acontecimentos narrados (história) e enunciados narrativos (discurso). Na narrativa singulativa narra-se uma vez o que se passou uma vez na história e sua fórmula é $1 \mathrm{~N} / 1 \mathrm{H}$, onde $\mathrm{N}$ significa o enunciado e $\mathrm{H}$ o acontecimento da história. Na narrativa iterativa conta-se (n)uma única vez o que se passou muitas vezes e sua fórmula é $1 \mathrm{~N} / \mathrm{nH}$, onde $\mathrm{n}$ denota a repetição do fato. Há ainda a narrativa repetitiva e a anafórica, pouco adotadas pelos autores. GENETTE, passim, s/d.

3 SARAMAGO, 1983, p. 11.

${ }^{4}$ SARAMAGO, 1983, p. 11. 
Mesclando sumário e pausa, ${ }^{5}$ o narrador vive o papel do cronista, seja por resumir os fracassos, seja por comentar suas causas, fingindo assumir os valores da época, como na exclamativa conclusão do parágrafo: "Mas Deus é grande". ${ }^{6}$

Por um enjambement que beira à blasfêmia - "Quase tão grande como Deus é a basílica de São Pedro que el-rei está a levantar", 7 o narrador incorpora técnicas de cinema ao focalizar o jogo de armar do rei, alternando-o com comentários que realçam a preciosidade das peças ou que justificam a imodéstia do personagem. No mesmo parágrafo, a câmera se desloca para o piso inferior e faz um flash da rainha que reza e espera, daí retornando o foco à tribuna real. O narrador prossegue com sua câmera, agora voltada para o ritual de preparação do soberano, interrompido pela entrada do franciscano que lhe arranca a promessa de construir Mafra. Dada a importância do encontro, causa dos demais acontecimentos da História e da narrativa, o narrador lhe concede um tratamento especial como cena, em contraste com o resto do capítulo, vazado em sumários. Na abertura deste único diálogo do capítulo (parágrafo $4^{\circledR}$ ), o narrador não só se mostra contemporâneo aos personagens ("Mas vem agora entrando ..."), ${ }^{8}$ como leva com ele o próprio leitor ("...e a tudo isto teremos de dar por feito e explicado,...")?

5 Sumário e pausa, assim como cena e elipse são categorias da duração da narrativa adotadas por Genette para relacionar o tempo da história ao tempo do discurso. Desta relação é possível observar as variações de velocidade, ou seja, as variações de ritmo da narrativa, verificando-se o quanto o tempo do discurso é menor que o tempo da história (casos de sumários e elipses), o quanto há de isocronia entre ambos (casos de cenas) e o quanto o discurso se alonga em relação ao progresso temporal da história (casos de pausas, descritivas ou digressivas).

${ }^{6}$ SARAMAGO, 1983, p. 12.

7 SARAMAGO, 1983, p. 12.

${ }^{8}$ SARAMAGO, 1983, p. 13.

9 SARAMAGO, 1983, p. 13. 
Em seguida surgem novos flashes, alternados e separados, sobre os soberanos que se preparam para o enlace sexual. Pausa para comentar a diferença de hábitos entre ambos, ele português, ela austríaca. Flash para a subida solene ao leito. Corte. A câmera se desloca e se fixa na cama, valiosa, importada. A pausa, contraponteada de elogios à peça e de deploração aos percevejos que a infestam, tem a duração do coito (e de um parágrafo). A elipse do ato sexual mediante o uso da pausa mostra o descompasso proposital entre a história (o ato) e o discurso (descrição da cama). Neste caso a pausa não serviu somente ao retardamento da narrativa, mas antes ao pudor do cronista invasivo. Concluída a ação, a narrativa retoma o seu passo: o casal se separa, os camaristas acorrem, a rainha tem sonhos eróticos com o cunhado, o rei sonha com seu falo poderoso.

Em suma, neste capítulo vigora o sumário e a pausa curta nele entremeada. A despeito da dominância do tratamento pictórico em detrimento do dramático ou cênico, a narração mantém-se viva graças à adoção do presente do indicativo e à participação do narrador, à semelhança das reportagens ao vivo que vemos na televisão. Por outro lado, a fala não serve à corroboração do sumário, nem sublinha o patético ou o sublime do episódio, como é costume em Saramago. Por ser única e situar-se no cerne do capítulo, ${ }^{10}$ a cena ganha importância não só porque reitera o axioma de que o escasso é relevante, mas principalmente porque representa o ato fundador da História (parte dela) e da história. Assistimos a um encontro de autoridades em que os poderes real e divino celebram um pacto cuja essência somente a eles pertence e cujas conseqüências atingem todos - plebe, narrador e leitores - condensados numa só voz.

${ }^{10}$ O capítulo tem onze parágrafos e oito páginas. O diálogo curto entre o rei, o bispo e o frade estão no $4^{2}$ e $5^{\circ}$ parágrafos, no transcurso da página 4 , ou seja, numa posição mediana que atesta a relevância do processo e, ao mesmo tempo, o equilíbrio na narração. 
Se ao término do capítulo o narrador comenta a onipotência dos reis, - "Não é vulgar em reis um temperamento assim, mas Portugal sempre foi bem servido deles", ${ }^{11}$ no início do capítulo $2^{\circ}$, encavalga, aos monarcas portugueses, os favores de Deus ao reino, "Bem servido de milagres, igualmente". ${ }^{12}$

Em O ano da morte de Ricardo Reis, os limites temporais da narrativa marcam a oposição entre uma chegada (a Lisboa) e uma partida (para o cemitério dos Prazeres $\cong$ morte). No capítulo inicial, o narrador nos coloca diante do personagem somente após ter feito, por quatro páginas, uma tomada panorâmica da cidade e mais especialmente do seu porto, no Tejo, por onde desembarcam, sob chuva miúda, de um vapor inglês, viajantes procedentes da América do Sul. Descreve a embarcação, focaliza o movimento de descida dos passageiros e suas bagagens, e se detém em "um homem grisalho, seco de carnes". ${ }^{13}$ Acompanha o percurso deste viajante comum, por ora inominado, até o Hotel Bragança quando então, no Livro de Registro, assentará seu nome, idade, estado civil, profissão, procedência. O tom impessoal é reforçado pelo ponto de vista externo do narrador, que coincide com a postura do próprio personagem ao revisitar sua terra natal como se fosse um estrangeiro, sem emoção ou sentimentalismos.

O aforisma - "Aqui o mar acaba e a terra principia" 14 - marca quiasmaticamente o fim e o início de uma dupla viagem. A primeira é física e objetiva pois representa a chegada do herói a sua terra. A segunda é psíquica e subjetiva pois implica, agora, um percurso em torno de si mesmo. A expressão - forma invertida do verso camoniano - "Onde a terra se acaba e o mar começa" ${ }^{15}$ - aponta para

\footnotetext{
${ }^{11}$ SARAMAGO, 1983, p. 18.

12 SARAMAGO, 1983, p. 19.

13 SARAMAGO, 1984, p. 15.

${ }^{14}$ SARAMAGO, 1984, p. 11.

${ }^{15}$ CAMÕES, 1996, p. 163.
} 
a grande aventura emigratória do povo português, iniciada no século XV, "diáspora de corpo e alma", na visão de Jorge de Sena. O retorno de Ricardo Reis em busca de sua identidade junto ao seu criador remete, de certo modo, à revisitação de Portugal a si mesmo, prenúncio do processo de autognose tematizado n'A jangada de pedra. No último capítulo, fecha-se o circuito temporal, por volta de agosto de 1936, oito meses após a chegada, em 29 de dezembro de 1935. A sentença final - "Aqui, onde o mar se acabou e a terra espera" - reforma a frase inicial, alterando-lhe o tempo verbal, do presente para o passado ("se acaba" para "se acabou"), e o sentido, pela troca do verbo ("principia" para "espera"). Nesta "espera" reside uma falta que não foi preenchida pelo personagem. Portugal permanece à espera de ações que lhe alterem o destino. Daí o sabor de inconclusão que se experimenta ao final da leitura de Ricardo Reis, forma reticente encontrada pelo autor para manifestar a sua inconformação.

O deslocamento em zoom para a figura do personagem no primeiro capítulo nos re-endereça para duas questões: a primeira, é a necessidade de acentuar a "pertença" e a "não-pertença" de um indivíduo à sociedade que o envolve; a segunda, é a de reforçar a contradição entre o sim e o não do intelectual - sua ambigüidade pois Reis está e não está no mundo. Daí o recurso simultâneo ao recorte, através do close, e à imersão no conjunto pelo plano geral. Trata-se de uma personalidade ao mesmo tempo cosmopolita e de feição apátrida, descaracterizada em sua "filiação". Apesar de português, Ricardo Reis vive no Brasil e, embora seja real como personagem, provém da ficção, a saber, d'As ficções do Interlúdio, de Fernando Pessoa.

\section{Tempos em tensão}

O $1^{\circ}$ capítulo da História do cerco de Lisboa tem forma bastante inédita em se tratando de uma narrativa. Abre sob a forma de uma cena dramática na qual se confrontam dois interlocutores. 
O diálogo se dá sem rubricas ou informações referentes ao tempo ou espaço. A única referência extralingüística é a menção a uma prancheta ou mesa onde um profissional - o revisor - desenha o sinal gráfico usado para "suprimir e apagar"16 letras e palavras - o deleatur. Aprende-o outro profissonal - o historiador - com o qual o primeiro entra em tensão. Apesar do amaneiramento das falas e da cortesia aparente, circulam sentimentos conflitantes e mesmo beligerantes entre eles.

O capítulo contém, de forma enigmática e nas suas entrelinhas, todo o tema da obra, seus motivos, seu start, seu desenvolvimento, seu desenlace. Nele está inscrita, de forma embrionária, a polêmica entre História e Literatura, entre realidade e fantasia, enfim, entre "verdade e mentira", cuja dialética se expressa na epígrafe da obra: "Enquanto não alcançares a verdade, não poderás corrigi-la. Porém, se a não corrigires, não a alcançarás. Entretanto, não te resignes. Do Livro dos Conselhos" ${ }^{17}$

Por trás de uma citação hipoteticamente alheia, o autor antecipa seu ponto de vista, concretizando-o através do "crime" do personagem, transformado em seu duplo. Verdade, Realidade ou História representam algo paradoxalmente consistente e mutável. Autor e personagem acreditam na Verdade desde que ela possa ser corrigida ou reinventada. E se isto não acontece - é o caso, por exemplo, do historiador que repete velhas verdades em seu livro não é possível alcançá-la. No entredito das falas, Raimundo demonstra a coragem necessária para efetuar uma transmutação de valores. Por um ato aparentemente imotivado e nocivo (diríamos, imaturo), reverbera a energia, ainda vívida, de uma individualidade até então massacrada por um mundo devorador e nivelador de consciências. A transgressão que o leva a a $(d u)$ lterar o texto alheio

\footnotetext{
${ }^{16}$ SARAMAGO, 1989, p. 11.

${ }^{17}$ SARAMAGO, 1989, p. 9.
} 
torna-o herói de si mesmo. "Santo DELEATUR, Que seria de nós se não existisse o deleatur, suspirou o revisor"18 e suspiramos nós.

O tempo total de duração do encontro e da conversa entre os interlocutores é, provavelmente, superior ao que registra a cena. A abertura e o fechamento do capítulo com a palavra do revisor com certeza lhe confere importância, mas não define os limites diacrônicos do acontecimento. Na estreiteza das falas, dá-se o reconhecimento dos falantes, seja pela auto-apresentação - “... nós, revisores, somos voluptuosos, (...)" -, ${ }^{19}$ seja pelo julgamento de um - "Os senhores autores vivem nas alturas, não gastam o precioso saber em despiciências e insignificâncias, (...)" ${ }^{20}$ - e de outro - "Creio perceber nas suas palavras uma certa amargura céptica (...).”21

Falamos em beligerância e explicamos: há no diálogo um litígio implícito e simbólico entre domínios. De um lado está o historiador, representando o saber constituído, douto, erudito, acadêmico, consagrado - "o senhor doutor é um sábio";22 do outro lado, está o revisor, de "não mais polimento que primeiras letras", ${ }^{23}$ representando a sabedoria popular. Além dessa guerra maior, de caráter intelectual, há um conflito surdo no plano dos sentimentos. As falas do historiador revelam uma benevolência arrogante rebatida com a ironia, o ressentimento, certa falsa modéstia e mesmo alguma subalternidade ferida do revisor.

O diálogo dever-se-ia "fechar" no tempo. Como não se enquadra no molde, fica-nos a impressão de sugerir, pela sua forma inconclusa, a própria incompletude e interminalidade dos discursos e, em decorrência, das enunciações definitivas sobre os fatos. O que

\footnotetext{
${ }^{18}$ SARAMAGO, 1989, p. 16.

${ }^{19}$ SARAMAGO, 1989, p. 12.

${ }^{20}$ SARAMAGO, 1989, p. 11.

${ }^{21}$ SARAMAGO, 1989, p. 13.

22 SARAMAGO, 1989, p. 16.

${ }^{23}$ SARAMAGO, 1989, p. 16.
} 
equivale a rasurar o estatuto da "última palavra" ou da "verdade definitiva" defendida por qualquer voz autoritária.

Também de chofre somos introduzidos n' O evangelbo segundo Jesus Cristo. Aqui somos postados diante de iconografia sacra que representa a cena da crucificação de Jesus, onde o narrador se representa como um espectador distanciado, arrastando-nos para a contemplação do quadro. Estamos no mundo de uma dupla representação, a da imagem plástica e a da narrativa:

O sol mostra-se num dos cantos superiores do rectângulo (...) e essa cabeça tem um rosto que chora, crispado de uma dor que não remite, lançando pela boca aberta um grito que não poderemos ouvir, pois nenhuma destas coisas é real, o que temos diante de nós é papel e tinta, mais nada. ${ }^{24}$

O Evangelho segundo Jesus Cristo tem vinte e quatro capítulos, dos quais o primeiro é a cristalização do último. O "enredo" da litografia inicial, de Albrecht Dürer, representa o ato, imobilizado ou eternizado, que se narra nas últimas páginas, fechando o ciclo. Assim, o capítulo primeiro é a culminância plasticizada da narração que começa efetivamente no capítulo $2^{\circ}$ e que se prolonga até o $24^{\circ}$. A circularidade entre o início e o fim se patenteia pela retomada de certo segmento: ao encerrar a descrição do $1^{\circ}$ capítulo, vemos (nós e o narrador), no fundo do quadro, a representação da ação de afastamento de um homem que "Leva na mão esquerda um balde e uma cana na mão direita". ${ }^{25}$ Ao encerrar a história (e a própria narrativa), o narrador refaz a última visão do personagem crucificado - Cristo - que, "...olhando para baixo, deu por um homem que se afastava com um balde e uma cana ao ombro". ${ }^{26}$

Num só fôlego, num só parágrafo, o observador representado e arguto finge ser um leigo, ou melhor, um sujeito não familiarizado

\footnotetext{
${ }^{24}$ SARAMAGO, 1991, p. 13.

25 SARAMAGO, 1991, p. 19.

${ }^{26}$ SARAMAGO, 1991, p. 445.
} 
com a Doutrina que rege a composição do quadro. Busca ocupar uma posição isenta de Fé ou de compromisso moral, tal como um esteta contempla o mundo: sem paixão, mas com vivo interesse. A descrição se faz no presente do verbo, num convidativo apelo à participação do leitor. O processo começa pelo canto superior esquerdo da iconografia onde brilha um sol alegórico, anunciando o sofrimento que emana de toda a obra.

A quebra da ilusão, operada pelo distanciamento dialético diante da representação plástica - "papel e tinta, mais nada" também se aplica à arte literária. Assim, desde logo, fica a advertência do ficcionista: o leitor está igualmente diante dos mesmos materiais usados na composição gráfica do livro que tem em mãos. Seja pelo ícone (a gravura), seja pelo símbolo (os signos lingüísticos), ${ }^{27}$ a realidade jamais é atingida: ela é uma cintilação que não se capta tal qual, como já disse um personagem do autor.

É impossível não associar a leitura do primeiro capítulo do Evangelho ao célebre ensaio sobre as palavras e as coisas ${ }^{28}$ onde o filósofo francês separa um momento preliminar - o capítulo inicial, intitulado "As meninas" - para abrir sua reflexão arqueológica sobre as Ciências Humanas. Lá, Foucault descreve, analisa e interpreta, minuciosamente, o famoso quadro no qual Velásquez, ao representar a família real com as "meninas" em primeiro plano, reserva para si próprio um lugar na imagem. A diferença entre os dois textos fica por conta da natureza do discurso subseqüente: investigação científica num, exercício literário noutro.

No quadro de Dürer retomado no Evangelho, há uma disposição espacial que privilegia a figura central do Cristo crucificado. A narrativa descritiva do mesmo mimetiza tal

\footnotetext{
${ }^{27}$ Valemo-nos aqui da nomenclatura semiótica de Peirce que compreende, no vértice-do-objeto, a classificação do signo como ícone, como índice e como símbolo. "A palavra é o símbolo por execelência". In: PIGNATARI, Décio. Semiótica e literatura, p. 25-66.

${ }^{28}$ FOUCAULT, 1981.
} 
configuração quando descreve a cena pelas beiradas, alcança uma espécie de clímax narrativo ao centrar-se em Jesus, e depois, sob forma de desenlace, volta-se para o homem que se retira com a água e o vinagre. Além de mimar a técnica de composição do pintor, o narrador também lhe toma emprestado o ponto de vista (a subjetividade) mas não propriamente a sua voz. No quadro está presente a alma do artista que o idealizou e que o concretizou. Sua emoção responde pelos traços do desenho e sua voz é a da Crença. No texto, o narrador se representa não só pela escolha dos caminhos imparciais da descrição, mas, principalmente, pelas suas intervenções, marcadas por uma pessoalidade crítica. Sua voz, portanto, é outra e não é a da Fé. Exatamente no momento mais culminante tal voz se revela questionadora da Fé, ao questionar a própria incompreensão de Cristo:

É ele, finalmente, este para quem apenas olham José de Arimatéia e Maria Madalena, este que faz chorar o sol e a lua, este que ainda agora louvou o Bom Ladrão e desprezou o Mau, por não compreender [grifo nosso] que não há diferença entre um e outro, ou, se diferença há, não é essa, pois o Bem e o Mal não existem em si mesmos, cada um deles é somente a ausência do outro. ${ }^{29}$

Podemos falar, de modo metafórico, em dois tempos: o tempo imobilizado, imortalizado, perenizado, ritualizado, enfim, eternizado no quadro de Dürer; e o tempo da contemplação crítica, que se insere no tempo bistórico de onde narrador/narratário observam a obra. Em outras palavras, na dicotomia tempo eternizado vs. tempo bistórico, pode-se entender tempo sagrado vs. tempo profano ou tempo da História Sagrada vs . tempo da História Humana. Da tensão entre os dois pólos, resulta o romance, cujo teor polêmico provém exatamente da justaposição das duas perspectivas do Evangelho - a sagrada e a profana. Há, pois, de saída, um diálogo intertextual entre o texto de José Saramago e as Sagradas Escrituras (Novo Testamento) na sua versão católica.

${ }^{29}$ SARAMAGO, 1991, p. 18. 
O capítulo inicial é um prólogo e, ao mesmo tempo, o anúncio do epílogo. Como prólogo especial que é, faz um convite ao leitor para "entrar" no quadro e, numa viagem pelo "túnel do tempo", assistir ao início da história. Apesar de ocupar apenas o capítulo $1^{\circ}$, a imagem e o ato de sua contemplação revestem-se de uma funcionalidade imprescindível para o sentido da obra. Caso este prólogo não existisse, o romance provavelmente seria apenas mais uma "Vida de Cristo”, entre tantas. O quadro opõe inação à ação, mito à realidade, passividade à atividade, fazendo refluir para dentro de si dois milênios de cultura cristã. Estamos presos na atempora-lidade da crucificação, assim como o sujeito contemplante parece estar magnetizado diante da iconografia. Logo a seguir, no entanto, mergulhamos no tempo histórico para, ao final, nos defrontarmos com o tempo humano de uma crucificação contextualizada. Entramos no tempo mítico pela contemplação de uma cena, e saímos para o tempo humano pela contemplação da mesma cena, "ao vivo". Ora, só a literatura é capaz de suscitar as associações que este processo evoca.

\section{Aberturas em sumários}

Emoldurando três segmentos, o romance Levantado do chão tem um capítulo inicial e um capítulo final que funcionam, respectivamente como prólogo e epílogo, graças à dimensão iterativa de ambos. Um e outro se espraiam, num discurso generalizante, por quatro páginas. O primeiro remete, retrospectivamente, a um passado difuso de exploração do latifúndio alentejano; o segundo, projeta, a partir de esperanças desencadeadas pelo 25 de Abril, um futuro igualmente enevoado.

A saga dos Mau-Tempo está contextualizada no capítulo inicial mediante a narração sumariada dos acontecimentos, no pretérito perfeito: "De guerra e outras pestes se morreu muito neste e mais lugares da paisagem". ${ }^{30}$ Valendo-nos de metáforas musicais,

${ }^{30}$ SARAMAGO, 1992, p. 12. 
verificamos que a obra começa com ritmo presto neste capítulo, onde o narrador busca, através de um sumário intemporal, fazer a história da ocupação dos latifúndios do Alentejo, a partir dos tempos imemoriais (a rigor, medievais). Os séculos se acavalam, céleres, por sobre o discurso. Os acontecimentos, sumariados ou elididos, quando muito surgem de forma metonímica: “...estradas reais, mais tarde nacionais (...)"; "...senhor rei ou duque ou duque depois real senhor, bispo ou mestre de ordem (...)". ${ }^{31}$

Logo a seguir, no segundo capítulo e por todo o primeiro segmento da narrativa (geração de Domingos e Sara da Conceição), há uma desaceleração abrupta com a narração de uma certa mudança de domićlio do casal, para depois, nos outros dois segmentos, acontecer uma retomada gradual de velocidade, como se passássemos do adágio para o andante e deste para o alegro. No último capítulo e epílogo da obra, retorna o adágio.

O $1^{\circ}$ capítulo é, pois, um grande sumário de sete parágrafos que serve de exórdio à narrativa. Nele o narrador se revela como o sujeito da enunciação capaz de escolher a forma de condução de discurso que lhe apetece: panorâmico, condensado, elíptico e acelerado ou restrito, distendido, manifestado e lentificado. Passando da primeira para a segunda forma, assim ele remata o capítulo: "Mas tudo isto pode ser contado doutra maneira" ${ }^{32}$

Por fim, em A jangada de pedra, ao longo de dez páginas, e sob o signo do "fabuloso", o narrador sumaria os acontecimentos insólitos que simultaneamente acorrem a cinco personagens distantes no espaço: Joana Carda e sua maravilhosa vara de negrilho; Joaquim Sassa e a pedra que salta; Pedro Orce e a percepção do rompimento da península; José Anaiço e o cortejo de pássaros; e, finalmente, Maria Guavaira e suas malhas intermináveis. Assim se organiza o primeiro capítulo do romance, fechado em cinco

\footnotetext{
31 SARAMAGO, 1992, p.12-13.

32 SARAMAGO, 1992, p. 14.
} 
enigmas, e aberto, daí em diante, para a dupla aventura, a da terra e a do mar. O sentido dos pequenos enigmas se articula ao sentido do grande enigma que é o descolamento da península Ibérica do continente europeu, tornando-se a "jangada de pedra". O narrador não volta aos pequenos enigmas para explicá-los. Pelo contrário, a explicação, também procurada pelos personagens, se torna irrelevante diante da polissêmica natureza da alegoria maior que envolve o texto. E este sentido já é induzido no capítulo inicial pela interrelação das questões pessoais com a situação maior de um povo em busca de sua identidade e de uma nova vocação nacional.

Concluindo, podemos dizer que os romances estudados revelam uma alternância de velocidade - um ritmo binário - que expressa uma diferenciação de sentido entre o capítulo inicial e os demais. No Memorial, o ritmo adágico e cinematográfico do capítulo inicial, que poderia aparentemente significar a atribuição de importância aos fatos ligados ao núcleo da família real, é desmentido pelo ritmo do resto da narrativa que concede aos oprimidos e derrotados cerca de 63\% do texto. Portanto, os "esquecidos" do tempo da História roubam a cena no tempo da Ficção. Em Ricardo Reis, o jogo entre os planos panorâmico e o close não opõe personagem ao contexto, antes os reflete um no outro, revelando uma relação "entre", um tempo-estagnação, uma entre-vida no domínio pessoal e público, numa época igualmente entrecortada por duas grandes guerras. No Cerco de Lisboa, o tempo ficcional se desdobra em duas folhas, igualmente simétricas apesar de tão distantes na História. A oposição rítmica binária se expressa na contenda entre dois textos, redobrada no paralelo entre guerras e amores. Também no Evangelho são dois os tempos que se contrastam em vários sentidos, o da História e o da Eternidade e o contraste se faz entre a temporalidade do enredo completo e a eternidade (ou ausência de temporalidade) do capítulo inicial. Aqui, os segmentos extremos, mais adágicos, apontam para o tempo de Deus e da fé, enquanto o segmento medial, mais acelerado, assinala o tempo do homem e da História. Em Levantado do chão, a espera de longos séculos se alterna com a esperança de uma nova geração. 
O passado (prólogo) sombrio e o futuro (epílogo) incerto correspondem a tempos não-mensuráveis, cuja iteração contrasta com a estrutura rítmica e freqüencial do resto da história. E, finalmente, na Jangada de pedra, o capítulo primeiro é o detonador de todas as alegorias subseqüentes, onde de um provável presente - ainda que incerto - aponta-se para um futuro desejável.

Enfim, há nestes romances de José Saramago a explícita intenção de singularizar a abertura de suas obras. Se na definição dicionarizada "pórtico" significa "átrio amplo com o teto sustentado por colunas ou pilares" (Aurélio), não podemos esquecer que, quanto à narrativa, é neste espaço que se inaugura a aliança entre autor e leitor e onde a amplidão é um convite para se adentrar num novo universo sustentado pela mão demiúrgica do narrador.

\section{Referências Bibliográficas}

CAMÕES, Luís Vaz de. Os Lusíadas. Org. introd. e notas Amélia Pinto Pais. Porto: Areal Editores, 1996.

FOUCAULT, Michel. As palauras e as coisas. Trad. Salma Tannus

Muchail, 2. ed. São Paulo: Martins Fontes, 1981.

GENETTE, Gérard. Discurso da narrativa. Lisboa: Vega, s/d.

PIGNATARI, Décio. Semiótica e literatura. São Paulo, Perspectiva, 1974.

SARAMAGO, José. Levantado do chão. São Paulo: Difel, 1982.

SARAMAGO, José. Memorial do convento. São Paulo: Difel, 1983.

SARAMAGO, José. O ano da morte de Ricardo Reis. 6. ed. Lisboa: Editorial Caminho, 1984.

SARAMAGO, José. A jangada de pedra. Lisboa: Editorial Caminho, 1986.

SARAMAgO, José. História do cerco de Lisboa. São Paulo: Companhia das Letras, 1989.

SARAMAGO, José. O evangelho segundo Jesus Cristo. São Paulo: Companhia das Letras, 1991. 


\section{Resumo}

Ao concluirmos um estudo em torno de seis romances de José Saramago, detectamos uma singular configuração nos capítulos de abertura. Memorial do convento e O ano da morte de Ricardo Reis se assemelham na forma cinematográfica com que são compostos os seus capítulos iniciais, marcando-se o primeiro pelo uso do close nos aposentos reais e o segundo pelo uso do zoom sobre o personagem que desembarca em Lisboa. Na História do cerco de Lisboa e em O evangelho segundo Jesus Cristo a abertura se torna um espaço de tensão, seja para opor duas concepções conflitantes de História - a oficial e a não-oficial -, seja para deflagrar a luta entre dois tempos do universo, - o eterno e o histórico. Por fim, a narrativa se abre por sumários em Levantado do chão e n' A jangada de pedra, sendo o primeiro de natureza retrospectiva, remetido ao passado alentejano, e o segundo de intenção recopilativa, voltado para o futuro da península.

\section{Abstract}

By the end of our study on six Saramago's novels, we could notice an special configuration in their first chapters. Memorial do Convento and $\mathrm{O}$ ano da morte de Ricardo Reis have both a cinematographical presentations, the first by making close into real rooms and the second by using zoom in a character who just arrive in Lisbon. At the first chapters of História do cerco de Lisboa and Evangelho segundo Jesus Cristo, there are spaces of tension, the first putting opposite conceptions of History the oficial and the non-official - and the other putting two different times in conflict - the eternal and the historical time. At last, in Levantado do chão and A Jangada de Pedra, the novels begin with summaries, one in a retrospective form toward the alentejano past and the other in the recopilative form toward the future of the peninsula. 